\title{
As Raízes Epistemológicas do Método Paulo Freire de Alfabetização
}

\author{
Jandrei José Maciel ${ }^{1}$ \\ Elcio Cecchetti ${ }^{2}$ \\ Ivo Dickmann ${ }^{3}$
}

\begin{abstract}
Resumo: O presente artigo é resultado de uma pesquisa de mestrado em educação desenvolvida no âmbito do Programa de Pós-Graduação em Educação da Universidade Comunitária da Região de Chapecó (Unochapecó), cujo objetivo principal foi investigar as raízes epistemológicas que influenciaram Paulo Freire na elaboração de seu método de alfabetização. A partir de uma abordagem qualitativa, o estudo baseia-se em uma pesquisa bibliográfica dos próprios escritos de Freire e de estudiosos de seu pensamento. Os resultados indicam que o método de alfabetização de Freire incorporou influências históricas, políticas e sociais vividas por ele no contexto do Nordeste brasileiro, onde existiam altas taxas de analfabetismo, desigualdade e pobreza. Atestam que seu método não se resume apenas codificar e decodificar letras e fonemas, mas em educar pessoas a se perceberem enquanto sujeitos conscientes de sua história e como agentes de transformação social.
\end{abstract}

Palavras-chave: Método de alfabetização. Paulo Freire. Epistemologia. Emancipação.

\section{The Epistemological Roots of the Paulo Freire Method of Literacy}

\begin{abstract}
This article is the result of a master's research in education developed within the Graduate Program in Education of the Community University of the Region of Chapecó (Unochapecó), whose main objective was to investigate the epistemological roots that influenced Paulo Freire in the elaboration of his method of literacy. Based on a qualitative approach, the study is based on a bibliographic research of Freire's own writings and of scholars of his thought. The results indicate that Freire's literacy method incorporated historical, political and social influences he experienced in the context of the Brazilian Northeast, where there were high rates of illiteracy, inequality and poverty. They attest that their method is not only about encoding and decoding letters and phonemes, but about educating people to perceive themselves as conscious subjects of their history and as agents of social transformation.
\end{abstract}

\footnotetext{
${ }^{1}$ Mestre em Educação. Professor de Filosofia e Ciências Humanas na Secretaria de Estado de Educação de Santa Catarina (SEE-SC). Santa Catarina, Brasil. E-mail: jandreimaciel@hotmail.com. Orcid: https://orcid.org/0000-0002-4885-4019

2 Doutor em Educação. Professor do Mestrado em Educação da Universidade Comunitária da Região de Chapecó (Unochapecó). Santa Catarina, Brasil. E-mail: elcio.educ@hotmail.com. Orcid: https://orcid.org/0000-0002-0946-320X

3 Doutor em Educação. Professor do Mestrado em Educação Professor do Mestrado em Educação da Universidade Comunitária da Região de Chapecó (Unochapecó). Santa Catarina, Brasil. E-mail: educador.ivo@unochapeco.edu.br Orcid: https://orcid.org/0000-0002-6293-8382
} 
Keywords: Method of literacy. Paulo Freire. Epistemology. Emancipation.

\section{Las Raíces Epistemológicas del Método Paulo Freire de Alfabetización}

Resumen: El presente artículo resulta de una investigación de maestría desarrollada en el Programa de Posgraduación en Educación de la Universidad Comunitaria de la Región de Chapecó (Unochapecó), cuyo objetivo principal fue buscar las raíces epistemológicas que influenciaron Paulo Freire en la elaboración de su método de alfabetización. Desde un abordaje cualitativo, el estudio es base bibliográfico, a partir de los proprios escritos de Freire y de estudiosos de su pensamiento. Los resultados indican que el método de alfabetización de Freire ha incorporado influencias históricas, políticas y sociales vivenciadas por él en el contexto del Nordeste brasileño, donde existían altas tasas de analfabetismo, desigualdad y pobreza. Atestan que su método no se resume apenas a codificar y decodificar letras y fonemas, sino de educar personas a persevérense en cuanto sujetos conscientes de su historia y como agentes de transformación social.

Palabras-clave: Método de alfabetización. Paulo Freire. Epistemología. Emancipación.

\section{Introdução}

Qualquer educador inevitavelmente depara-se diante do desafio da escolha de um método de ensino para concretizar os objetivos pretendidos por sua ação. Percebemos na atualidade a coexistência de métodos educacionais baseados em currículos fixos, competitivos e produtivistas, amparados por metas, avaliações e testes de qualidade, que apenas desenvolvem o aspecto cognitivo do educando, sem tecer relações com sua realidade social e nem com os dilemas da vida cotidiana. Em Paulo Freire, o método não opera no vazio e nem se refere a uma escolha qualquer, pois está integrado às pretensões políticas, ideológicas e sociais que a educação proporciona.

Debruçar-se sobre o pensamento de Freire e seu método, nos dias atuais, é certamente um desafio, pois vivemos práticas educacionais enraizadas com intenções prédeterminadas, métodos e fórmulas prontas, quase que dogmáticas. Partimos da análise de Freire como um educador comprometido com a realidade onde vive, que objetiva uma educação libertadora para e com o povo. Freire parte do princípio de que toda a ação humana tende a práxis (DICKMANN, 2015), entendida aqui como transformação do mundo, como relação entre ação e reflexão (FREIRE, 2016).

No anseio de realizar uma prática educativa com sentido e que correspondesse aos anseios do educando e dos propósitos esperados pela educação, o método de alfabetização 
idealizado pro Freire ultrapassa a aprendizagem mecânica e técnica das palavras. Para ele, a educação deve estar comprometida com a libertação, com a politização e conscientização, partindo da realidade do educando.

Freire contribuiu para a criação de uma consciência sobre a educação e seu papel na sociedade, defendendo que ela provoque nos educandos uma consciência crítica sobre si mesmo e sobre seu papel na sociedade. Apresenta, também, uma nova relação entre educador e educando, na qual o primeiro deixa de ser detentor único do saber e de ver o segundo como um ser vazio a ser preenchido. Sua proposta pedagógica coloca ambos os envolvidos no processo formativo e educativo em igualdade de saberes, não existindo um sujeito superior ao outro. Cabe ao educador, neste sentido, o papel de organizar os saberes trazidos pelo educando e provocar nele uma consciência crítica de sua realidade levandoo à descoberta de saídas aos problemas enfrentados.

Neste trabalho, a partir de leituras e análises das obras de Freire e de alguns de seus estudiosos, pretendemos responder à seguinte pergunta: quais são as raízes epistemológicas que embasam o método Paulo Freire de alfabetização?

O objetivo central consiste em compreender quais foram as principais correntes e teorias filosóficas, sociológicas e políticas que embasaram Freire e que deram origem ao seu método, historicamente caracterizado por sua ação em favor de uma educação libertadora, esperançosa e utópica.

A relevância deste estudo está em enaltecer os pressupostos, princípios e práticas do método Paulo Freire numa concepção popular e libertadora de educação, para justificar a sua atualidade e validade enquanto método que valoriza o educando e o educador igualmente. Outro motivo que justifica esta pesquisa é analisar a importância de Freire como um educador que criou uma nova forma de pensar e de fazer educação.

O método pensado por Freire está pautado em princípios de emancipação e libertação dos sujeitos através do diálogo e troca de saberes. Ele demonstra que o educando adquire uma consciência crítica e histórica na relação humana, onde os envolvidos neste diálogo são considerados sujeitos com direito de expressar a palavra e sua leitura de mundo, e encontrar caminhos para a construção e transformação da sociedade.

Nesse sentido, Paulo Freire foi um educador comprometido com uma proposta de educação libertadora, conscientizadora e comprometida, na qual o educando é 
considerado em sua condição humana, com a possibilidade de se tornar agente de sua história, de seu presente e de seu futuro. Mais do que criar um método de alfabetização, Freire formulou uma teoria do conhecimento, uma epistemologia, que transborda os limites de sala de aula, que ultrapassa o conteudismo e o tecnicismo e valoriza a formação integral do educando, considerando seu contexto histórico, social, cultural e econômico.

Metodologicamente, a pesquisa é de abordagem qualitativa, do tipo bibliográfica. $\mathrm{O}$ texto que segue estrutura-se em três momentos: primeiramente, caracterizamos o método de alfabetização pensado e aplicado por Freire nos anos de 1963 e 1964, destacando as suas cinco fases de organização. Na sequência, identificamos as principais influências teóricas que influenciaram Freire em sua opção pela educação libertadora. Por fim, analisamos o método de Paulo Freire como fruto de uma amálgama de influências epistemológicas e históricas decorrentes das suas concepções de mundo e das suas experiência de vida, mas com uma originalidade própria. Por fim, apontaremos que o método de Freire supera a mera alfabetização, a apreensão mecânica da palavra e da leitura, porque pauta-se na conscientização do educando, na politização, no diálogo e na transformação da realidade.

\section{As Influências Teóricas do Método Paulo Freire de Alfabetização}

O que atualmente é conhecido como "Método Paulo Freire de alfabetização" surgiu com o trabalho realizado por Freire na década de 60 juntamente com o Movimento Cultura Popular (MCP) em uma periferia da cidade de Recife/PE. Inicialmente foi uma experiência com cinco educandos, conforme relato do próprio Freire (1980). No entanto, a mais notável experiência foi realizada em Angicos/RN, onde foram alfabetizados 300 trabalhadores em 45 dias.

Num contexto empobrecido e excludente em que se encontrava o Nordeste brasileiro nas décadas de 1950 e 1960, Paulo Freire, baseado em suas experiências educativas com trabalhadores e nos círculos de cultura ${ }^{4}$, propõe um projeto educacional, conscientizador, democrático e libertador. O seu método propunha a valorização dos

\footnotetext{
${ }^{4} \mathrm{O}$ círculo de cultura tem por princípio que ninguém ocupe o lugar proeminente ou de maior importância. O professor é tido como o monitor ou coordenador do diálogo, propõe um saber que é construído em conjunto, onde ele também aprende ao mesmo tempo que ensina. O diálogo é tido como uma maneira de se valorizar os saberes a palavra dos educandos. (STRECK, REDIN, ZITKOSKI, 2010).
} 


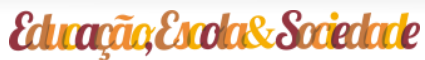

sujeitos, comprometendo-se verdadeiramente com homens e mulheres excluídos da sociedade ou que estavam destinados a serem meros trabalhadores obedientes.

Angicos não foi a primeira experiência de aplicação do método, mas foi a experiência que mais teve olhares, pois tratava-se da terra natal do então presidente da república, João Goulart. O objetivo era alfabetizar trabalhadores rurais, num período de 40 horas. A preparação dos professores se dava anteriormente ao trabalho, captando expressões vocabulares utilizadas pelas pessoas da comunidade.

O método de alfabetização de Paulo Freire começa pela busca do universo de palavras. Isso ocorria de maneira muito simples, através de conversas. Esse primeiro momento era fundamental, porque fornecia o grau de conscientização existente na comunidade. Ao mesmo tempo era deste ambiente que eram recolhidas as palavras geradoras que, carregadas de sentido existencial dos educandos e da comunidade onde viviam, serviam de base para o processo de alfabetização.

De acordo com Pelandré (2009), uma das marcas que o método freiriano apresentava era de trabalhar com o próprio material fornecido pela comunidade. Depois do diálogo, da inserção dos educadores na realidade do educando, se recolhiam, por meio de pesquisa, as palavras geradoras. A chave do sistema a ser empregado se encontra, portanto, no trabalho sobre as palavras geradoras, que são as palavras-chave cuja decomposição em fonemas possibilita o surgimento de novas combinações. No universo de vocábulos obtidos, escolhiam-se os vocábulos cujas dificuldades fonêmicas deveriam ser dominadas pelo analfabeto.

Ainda de acordo com Pelandré (2009), depois de colocar em fichas, a palavra geradora passava pela representação visual, sendo associada ao objeto que ela representa. Discutia-se a situação da comunidade ou a situação problema por meio da palavra e imagem projetada no slide. Para Freire, a alfabetização é a conquista que o homem e a mulher fazem da palavra, oriunda de seu próprio contexto, de seu mundo, e que se torna uma ferramenta para aprender a decodificar, formar e ler outras palavras.

O método estava organizado em cinco fases e encontra-se descrito nas obras de Freire, especialmente na Pedagogia do oprimido e em Educação como prática de liberdade. A primeira fase refere-se a descoberta do universo vocabular, efetuada anteriormente ao processo de aplicação do programa de alfabetização, por meio de encontros informais com os habitantes do contexto que se procura atender. Não só se 
retém as palavras mais carregadas de sentido existencial, também as expressões típicas do povo: as formas de falar particulares, palavras ligadas à experiência do grupo, especialmente à experiência profissional. As palavras geradoras deveriam nascer desta procura e não de uma seleção que se efetua, individualmente, em um gabinete de trabalho, por mais perfeita que ela seja do ponto de vista técnico.

A segunda fase se caracterizava pela seleção de palavras, dentro do universo vocabular. Esta seleção necessitava ser submetida aos seguintes critérios: a) riqueza silábica; b) dificuldades fonéticas - as palavras escolhidas deveriam responder às dificuldades fonéticas da língua e serem colocadas em ordem de dificuldade crescente; e c) conteúdo prático da palavra, o que implica em procurar o maior vínculo possível da palavra com a realidade de fato, social, cultural e política. De acordo com Brandão (1981), o método Paulo Freire propõe um critério de seleção das palavras que não a torna apenas como um instrumento de leitura, mas um meio para perceber, refletir e criticar a própria realidade.

A terceira fase diz respeito a criação de situações existenciais típicas do grupo com o qual se trabalha. Estas situações desempenham o papel de "desafios" apresentados aos grupos. Trata-se de situações problemáticas, codificadas, que levam em si elementos para que sejam decodificados com a colaboração do coordenador. Uma palavra geradora pode englobar a situação completa ou referir-se somente a um dos elementos da situação.

A quarta fase é de elaboração de fichas indicadoras que ajudam os coordenadores do debate em seu trabalho. As fichas de cultura, conforme Brandão (1981), eram representações em desenhos feitos em cartazes ou projetados em slides que tinham por objetivo gerar o debate e a troca de ideias entre educandos e educador e entre os próprios educandos. As imagens projetavam situações que lhes era familiar facilitando assim a apreensão e compreensão, levando-os a perceberem-se enquanto seres com cultura e também construtores de cultura. Dentre os conceitos apresentados estavam "trabalho", "diálogo", "mundo", "natureza", "homem”, "sociedade" "voto", “salário”, etc.

A quinta fase é o momento de elaboração das fichas com as famílias fonêmicas de cada palavra geradora (FREIRE, 1980). Uma vez elaborado o material, em forma de dispositivos ou cartazes, constituídas as equipes de supervisores e de coordenadores, devidamente treinados nos debates relativos às situações já elaboradas, e de posse de suas fichas indicadoras, poderia se inicia o trabalho de alfabetização. Optando sempre por uma 
forma diferente de organização da aula, as turmas eram organizadas em círculos, para que todos participassem dos debates de forma horizontal.

Com isso, identificamos que o método de alfabetização de Freire incorpora princípios chaves, tais como o diálogo, a politização e a conscientização como fatores essenciais à educação libertadora. Inicialmente, o educador necessita reconhecer os saberes do educando, já que este conhece muitas coisas que são de sua realidade. Atitude esta inexistente na educação bancária, que objetiva, como o próprio nome sugere, depositar conteúdos nos alunos.

O diálogo é para Freire um fator preponderante na mediação do educadoreducando. Quando a educação se pauta no diálogo, ela antecipadamente demonstra a intenção do ato educativo, pois valoriza a história, os conhecimentos e as condições de vida dos educandos, em oposição à educação bancária, tecnicista, monóloga, que coloca o estudante na condição de sujeição e submissão ao professor e ao próprio ato educativo.

Para Freire, a atitude dialógica é, antes de tudo, uma atitude de amor, humildade e fé na humanidade, no seu poder de fazer e refazer, de criar recriar, de ser construtor da própria história (FREIRE, 2016). A atitude dialógica deve perpassar o tripé educadoreducando-objeto de conhecimento. Partindo da realidade do educando, o diálogo iniciase antes mesmo do ato educativo, no processo de captação de pesquisa e organização do universo vocabular de sua realidade e de seu povo.

Com base nas rodas de conversa, o educador organiza os conhecimentos de forma a despertar no educando a motivação para aprendê-lo. A atitude dialógica também perpassa a relação entre o educador-educando, na sua relação de confiança, de descobertas, organização e mediação do conhecimento, reconhecendo-se como iguais no processo, onde existem apenas diferenças de funções: o educador tem a função de mediatizar os conhecimentos apresentados pelo educando com o mundo, a realidade onde esse sujeito se insere.

Freire jamais deixou de lado a luta pela superação da opressão, desigualdade e do analfabetismo, e considerou que a transformação da sociedade só é possível através da educação, já que ela possibilita que os sujeitos se reconheçam como agentes transformadores. Isso está claro um dos primeiros princípios do método de Freire, a politicidade do ato educativo, pois não existe educação neutra. Como assinala Feitosa (1999, p. 46-47): 
O alfabetizando é desafiado a refletir sobre seu papel na sociedade enquanto aprende a escrever a palavra sociedade; é desafiado a repensar a sua história enquanto aprende a decodificar o valor sonoro de cada sílaba que compõe a palavra história. Essa reflexão tem por objetivo promover a superação da consciência ingênua - também conhecida como consciência mágica - para a consciência crítica. Na experiência de Angicos, assim como em outros lugares onde foi adotado o método, as salas de aula transformaram-se em fóruns de debate, denominados 'Círculos de Cultura'. Neles, os alfabetizandos aprendiam a ler as letras e o mundo e a escrever a palavra e também a sua própria história.

Freire desperta a importância política do ato de educar quando coloca nela a possibilidade de mudança da realidade, quando o educando se percebe como um sujeito de transformação e libertação, enquanto outras propostas tendem a colocá-lo na condição de obediência e sujeição às ordens e leis estabelecidas pelas elites econômicas, políticas e do conhecimento.

\section{As Influências Teóricas do Método Paulo Freire de Alfabetização}

A análise sobre as raízes do método de alfabetização de Paulo Freire nos apresenta várias fontes teóricas, históricas e políticas que o influenciaram. Dentre as principais correntes de pensamento estão os intelectuais brasileiros da década de 50 e 60, o humanismo cristão, devido a sua ligação ao catolicismo progressista, especialmente do personalismo de Mounier, do existencialismo e de outros grandes nomes do pensamento ocidental, tais como Hegel, Marx e Husserl.

O contexto histórico de Freire era rico em significado para a elaboração de seu projeto educacional. Destaca-se a infância pobre e sofrida no Nordeste brasileiro, a forma como aprendeu a ler com os pais na sombra do quintal de casa, a sua formação em Direito na Universidade do Recife. Merece destaque a sua ligação ao Serviço Social da Indústria (SESI), onde foi diretor do Setor de Educação e responsável por coordenar os trabalhos dos professores, dialogar com alunos e seus familiares. Foi neste trabalho que Freire passou a compreender a classe trabalhadora, sua forma de aprender o mundo, através de uma linguagem própria, partindo da realidade.

Outra experiência que marcou o período foi a sua participação no Movimento de Cultura Popular (MCP), criada pelo prefeito de Recife, Miguel Arraes, em 1958. A ação consistiu na criação de escolas para o povo, em espaços disponíveis na comunidade, servindo, inicialmente, para a alfabetização de adultos. Foi nessa experiência que Freire 
formulou seu método de alfabetização.

As principais referências teóricas de Freire, nesta época, advieram dos estudiosos do Instituto Superior de Estudos Brasileiros (ISEB), fortemente marcados pelo nacionalismo desenvolvimentista, cujo objetivo era difundir as ciências sociais como fator essencial para a compreensão da realidade brasileira.

Além do personalismo de Mounier, as filosofias existencialistas também exerceram considerável influência nas concepções de Freire. As noções de tempo e espaço, assim como, do caráter histórico do humano foram apropriadas do pensamento de Heidegger, Jasper e Marcel. Freire buscou ainda iluminar as dúvidas e seus projetos através de constantes e diversas leituras, especialmente das obras de Husserl, Hegel e, sobretudo, Marx.

Quando se refere à fenomenologia, Husserl foi um dos pensadores lidos por Freire e que influenciaram a sua concepção de educador/mundo. Em Husserl aprendeu que o mundo natural não constitui uma evidência primeira da existência, uma vez que não se autopercebe; esta deve ser procurada no próprio sujeito, na consciência do eu reflexivo, que se auto experimenta. Para Husserl, é o eu, através da reflexão e das cogitações, que dá sentido, validade e existência ao mundo.

Para Freire a consciência jamais poderia se reduzir a uma subjetividade absoluta, como consciência da totalidade. Em Husserl a consciência sempre é de algo. Contudo, Freire vai além desta definição, pois para ele a consciência se constrói coletivamente com outros homens e mulheres.

O pensador alemão Hegel é também facilmente notado no pensamento freiriano, pois é a partir dele que o humano é considerado, não só como consciência, mas como autoconsciência. Para Freire, é necessário ao educando perceber-se enquanto ser consciente em si para transformar-se em uma consciência de si, para uma consciência com seus semelhantes, sua realidade e seu mundo.

Outra influência forte no pensamento freiriano adveio de Karl Marx, que propõe como referencial de análise o materialismo histórico dialético. Para ele o conhecimento e a visão de mundo estão ligados às condições materiais em que os indivíduos estão inseridos. A transformação da consciência passa pela transformação social. Por isso, na concepção de Freire, a educação tem por objetivo promover a ação e a libertação.

No pensamento de Marx, a questão gnosiológica é apreendida como atividade, 
como prática. O conhecimento para ele está irremediavelmente ligado ao trabalho como objeto de transformação do mundo, enquanto atividade especificamente humana. Assim sendo, o trabalho aparece como processo fundante do sujeito, como práxis, ação refletiva e planejada. (FEITOSA, 1999). Para Marx, este esforço de desvelamento do real é visto como "consciência da práxis" ao qual Freire vê como "admiração e readmiração do admirado", como conscientização. Ao ser perguntado sobre se se considerava ou não um marxista, Freire assim respondeu:

Não quero dizer que eu sou hoje um 'expert em Marx', ou 'que sou um marxista'. Por uma questão até de humildade. Eu acho que é muito sério dizer alguém ser marxista. É preferível dizer que eu estou tentando tornar-me. É a mesma coisa em relação à minha opção cristã. Eu sou um homem em procura de tornar-me um cristão. [...] Pois quanto mais eu me encontrei com Marx, direta ou indiretamente, tanto mais eu entendi os evangelhos que eu lia antes com uma diferente interpretação. Quer dizer, no fundo, Marx me ensinou a reler os evangelhos. Para muita gente, isso é absurdo. Para certos marxistas mecanicistas, que para mim não entenderam Marx, e que não só distorcem, mas obstaculizam o desenvolvimento do pensamento marxista, para esses eu sou um contraditório, e não vou deixar de ser jamais um idealista, representante de uma pedagogia burguesa. Para certo tipo de cristão mecanicista também, tão reacionário quanto estes pseudo-marxistas, eu sou um endemoniado contraditório. Eu não vejo nenhuma contradição à minha opção cristã pretender uma sociedade que não se funda na exploração de uma classe por outra. Em última análise, devo dizer que tanto a minha posição cristã quanto a minha aproximação a Marx; ambas jamais se deram ao nível intelectualista, mas sempre referida ao concreto. Não fui a Marx por causa delas. O meu encontro com elas é que me fez encontrar Marx e não o contrário (FREIRE, 1979, p. 38).

Freire, quando ainda era moço, foi aos mangues, córregos e aos morros de Recife, às zonas rurais de Pernambuco, trabalhar com favelados e camponeses. Ao ver a realidade dura da exploração, da negação da dignidade humana, Freire incorpora influências marxistas e as une com o humanismo cristão, progressista, com fortes pinceladas do pensamento de Gramsci.

O personalismo é outra marca forte do pensamento freiriano, sobretudo na relação dialética estabelecida entre o sujeito e o objeto de conhecimento. De acordo com Simões (1981), o personalismo tem como uma das ideias centrais a noção de que o homem não se reduz às determinações impostas pela natureza ou vida em sociedade. E esta também é a noção antropológica de homem para Freire, pois para ele, o homem "pessoa" não pode ser visto como um mero objeto do mundo ao qual pertence, pois é sujeito, é capaz de atuar intencionalmente no mundo. $\mathrm{O}$ personalismo de Mounier defende a noção de que o 
homem deve conviver em comunhão com outros homens, também não deve ser vítima de explorações, nem vítima de regimes individualistas e burgueses, onde o "ter" é preferido ao "ser". Assim como Mounier, Freire combate a coisificação do homem e sua alienação pelos opressores (SIMÕES, 1981).

Com base na compreensão da função social da educação e seu papel transformador, seja pela noção marxista da relação entre homem, natureza, pela noção dialógica e pela noção antropológica personalista, Freire organiza seu método pautado em cinco fases, já apresentadas anteriormente, dialógicas e com um compromisso político. Freire destaca que a sociedade brasileira vivia em um período de transição e para isso era necessária uma educação que fosse capaz de promover a passagem da transitividade ingênua à crítica, evitando, sobretudo, a massificação (FREIRE, 1980).

Outra categoria fundamental do pensamento de Paulo Freire a concepção antropológico-cultural de comunicação . O humano, dotado de consciência que, entre outras coisas, reflete a realidade exterior, põe-se diante da natureza e a conhece, realizando uma relação entre realidade interior (esfera lógico-psicológica) e realidade exterior (esfera cosmológica). É a relação sujeito/objeto, ponto de partida para toda e qualquer concepção do mundo. (MACIEL, 1963).

O diálogo em Freire só ocorre na condição de igualdade representada em uma relação horizontal de A com B. Essa relação deve estar nutrida de amor, humanidade, esperança, fé, confiança. Por isso só o diálogo comunica. E quando os dois polos do diálogo se ligam com amor e esperança, instala-se então uma relação de simpatia entre ambos. Só aí há comunicação. (FREIRE, 1980).

A vocação inata do homem em "Ser Mais” impulsiona-o na busca pela libertação. Daí que Freire considera que a conscientização da situação existencial dos oprimidos era o primeiro passo para a libertação. Por isso, a necessidade de uma educação pautada no diálogo entre educador e educando, sem a doação de conhecimento e a imposição de verdades "Sempre confiáramos no povo. Sempre rejeitáramos fórmulas doadas. Sempre acreditáramos que tínhamos algo a permutar com ele, nunca exclusivamente oferecerlhe". (FREIRE, 1979, p. 102).

\section{A Concepção de Alfabetização em Freire}


Paulo Freire, na década de 1960, iniciou uma experiência revolucionária na alfabetização de adultos, tendo sua experiência mais notável a realizada na cidade de Angicos, onde $70 \%$ da população adulta era analfabeta e dos $30 \%$ restantes, $10 \%$ eram semianalfabetos, conforme apresenta Gadotti (2014).

A partir da experiência como educador popular e no diálogo com trabalhadores, Freire propôs um método de alfabetização diferenciado dos tradicionais. Sua proposta partia da condição do educando, do seu estado de opressão, coisificação, e propunha a conscientização a partir do diálogo, fazendo-o perceber-se enquanto sujeito de direito, que pode e deve ser um agente construtor da sociedade. A proposta Freiriana não estava estruturada como um mero instrumento de alfabetização, mas era conscientizadora, dialogal, politizadora, partindo do mundo do educando.

Portanto, Freire propôs mudanças significativas aos tradicionais programas de alfabetização de adultos presentes à época:

\begin{abstract}
Ao invés de escola noturna para adultos, em cujo conceito há certas conotações um tanto estáticas, em contradição, portanto, com a dinâmica do Trânsito, lançamos o Círculo de Cultura. Como decorrências, superamos o professor pelo coordenador de debates. $\mathrm{O}$ aluno, pelo participante do grupo. À aula, pelo diálogo. Os programas por situações existenciais, capazes de, desafiando os grupos, levá-los, pelos debates das mesmas, a posições mais críticas (FREIRE, 1963, p. $13)$.
\end{abstract}

As alterações demonstram o objetivo de uma alfabetização diferenciada, conduzida por um docente mediador de debates, que conduz os educandos a uma mesma compreensão da realidade e das palavras. Entende que o jovem e o adulto eram portadores de um conhecimento que fundamenta sua cultura, suas experiências. Portanto, a alfabetização e conscientização deveriam partir de seu mundo, das suas significações. Por isso, inicialmente, há necessidade de buscar as palavras geradoras, que são extraídas do seu universo vocabular, e que serão temas de discussão nos círculos de cultura.

Não por acaso, a primeira fase do método é a do levantamento do universo vocabular, onde a entrevista com os futuros educandos e o preenchimento de fichas ajudam a fazer a coleta dos dados pessoais, comunitários e perspectivas em relação a alfabetização. A proposta Freiriana de "entrevista" e contato com o educando, não está ligada apenas ao fato relativo ao programa de alfabetização, mas também como uma forma engajamento do educador o mundo do educando, para que seus mundos se 
aproximem, integrando-se a esta realidade, para posteriormente ser o fomentador de debates, propondo uma educação para e com ele.

Na segunda fase do método, caracterizada pela seleção do universo vocabular, a meta era assegurar a aprendizagem baseada no som e em métodos que valorizam o significado do texto lido. Freire valorizava ambos os processos, tanto a importância fonêmica e silábica quanto o seu significado pragmático. Na seleção das palavras geradoras encontramos a sua riqueza fonêmica e seu potencial de transformação e engajamento do educando em sua realidade. Freire apresentava, com entusiasmo, o fato de que, geralmente, levava-se em torno de um mês e um mês e meio para que um grupo de 20 a 25 analfabetos estivessem lendo jornais e escrevendo pequenos bilhetes, além de discutir problemas locais, regionais e nacionais. (FREIRE, 1980).

Os materiais utilizados para a alfabetização, na proposta do método freiriano, eram um quadro negro (de baixo custo), um stripp-film (ou fotograma) que custavam em torno de quatro a cinco mil cruzeiros e um projetor de fabricação polonesa, que custava em torno de sete mil e oitocentos cruzeiros (FREIRE, 1980).

Freire optou pela não elaboração de cartilhas, pois acreditava que estas não se aproximam da realidade dos educandos. Para ele, as palavras devem ser criadas e não "doadas". O alfabetizando é o sujeito e não objeto da alfabetização. Por isso, em sua opinião, as cartilhas não contribuem com o processo de criação do sujeito de alfabetização. As cartilhas ensinavam pelo método da repetição de palavras soltas ou de frases criadas de forma forçosa que comumente se denomina como "linguagem de cartilha". Freire (1980, p. 21) relata que,

\footnotetext{
Inicialmente me parece interessante reafirmar que sempre vi a alfabetização de adultos como um ato político e um ato de conhecimento, por isso mesmo, como um ato criador. Para mim seria impossível engajar-me num trabalho de memorização mecânica dos babe-bi-bo-bu, dos la-le-li-lo-lu. Daí que também não pudesse reduzir a alfabetização ao ensino puro da palavra, das sílabas ou das letras. Ensino em cujo processo o alfabetizador fosse 'enchendo' com suas palavras as cabeças supostamente 'vazias' dos alfabetizandos. Pelo contrário, enquanto ato de conhecimento e ato criador, o processo da alfabetização tem, no alfabetizando, o seu sujeito.
}

Freire destaca que o momento da aquisição da linguagem é em si um momento criador, que deve partir do educando e não como uma imposição ou doação do educador para ele. Cabe ao educador a tarefa de coordenar os debates, organizar as fichas de roteiro, 
elaborando materiais que façam sentido para a vida do educando, proporcionando momentos de reflexão no círculo de cultura.

Em relação à concepção de escola e de como conduzir a alfabetização, Freire (1980, p. 103) destaca que:

De acordo com as teses centrais que vimos desenvolvendo, pareceu-nos fundamental fazermos algumas superações, na experiência que iniciávamos. Assim, em lugar de escola, que nos parece um conceito, entre nós, demasiado carregado de passividade, em face de nossa própria formação (mesmo quando se lhe dá o atributo de ativa), contradizendo a dinâmica fase de transição, lançamos o Círculo de Cultura. Em lugar do professor, com tradições fortemente 'doadoras', o Coordenador de Debates. Em lugar da aula discursiva, o diálogo. Em lugar dos 'pontos' e de programas alienados, programação compacta, 'reduzida' e 'codificada' em unidades de aprendizado.

Com isso, concluímos que a alfabetização não pode se fazer de cima para baixo, nem de fora para dentro, como uma doação ou uma exposição. Por isso, a importância do Círculo de Cultura. Neste, o educando é tido como o participante do grupo e o professor é substituído pelo Coordenador de Debates. A aula tradicional dá lugar ao diálogo, uma vez que, se a educação não partir do diálogo, da relação de igualdade entre educador e educando, acaba sendo dominadora, doadora e alienante, distanciando-se de um processo criativo, conscientizador e politizador - o que justamente o seu método de alfabetização propõe.

\section{Considerações Finais}

O método Freiriano de educação parte do diálogo entre educador e educando e da experiência de vida e do mundo do educando, através das palavras geradoras, que são colhidas pelo educador quando do primeiro contato com a comunidade onde o programa de alfabetização seria implantado. O diálogo é fundamental na construção de relações de confiança e respeito com o educando, para que ele mesmo se alfabetize enquanto toma consciência de seu mundo, de sua condição de vida.

O método Paulo Freire propõe ainda uma educação pautada na conscientização e na politização, partindo das palavras geradoras que são colhidas do mundo da práxis do educando para conscientizá-lo de sua condição como um ser construtor de cultura. E não uma educação mecanizada que se restrinja na mera associação entre palavras e objetos 
representados e de uma divisão silábica. Para Freire, a educação tem um compromisso com o educando e com a transformação da realidade.

Podemos concluir que o método Paulo Freire é fruto de um mosaico de influências teóricas, epistemológicas, históricas, políticas e sociais, mas que é inovador quando propõe uma educação que vai além da própria alfabetização, pois parte do universo do educando, de seu mundo, de suas palavras e se propõe a conscientizá-lo.

O método Paulo Freire pode ser considerado como revolucionário em seu contexto histórico e político, com potencial para enfrentar a problemática histórica do analfabetismo, se não tivesse sido abortado pelo golpe militar de 1964. Talvez a situação social e educacional em nossos dias fosse outra, caso o regime político tivesse sido democrático e o método de Alfabetização de Freire tivesse sido adotado a todas as regiões do país.

Na atualidade, em meio ao crescente conservadorismo dos costumes e à crescente exploração neoliberal da força produtiva da população, cabe aos educadores rediscutir os propósitos do ensino, as metodologias adotadas e as intenções que permeiam a educação. Que haja mais rodas de conversas, momentos de formações e de reflexão sobre a práxis e menos transmissão deliberada de saberes descontextualizados.

Paulo Freire continua desafiando a pensar sobre as metodologias e intencionalidades educativas, sobretudo, desafiando a perceber em que medida as práticas pedagógicas partem do diálogo e conduzem efetivamente à construção de uma práxis crítica, libertadora e emancipadora.

\section{Referências}

BRANDÃO, C. R. O que é método Paulo Freire.18 ed. São Paulo, Brasiliense. 1981.

DICKMANN, I. A formação de educadores ambientais: contribuições de Paulo Freire. 2015. Tese (Doutorado em Educação). Programa de Pós-Graduação em Educação, Universidade Federal do Paraná, Curitiba, 2015. 
FEITOSA, S. C. S. Método Paulo Freire: princípios e práticas de uma concepção popular de educação. Dissertação (Mestrado em Educação- Filosofia da Educação). Faculdade de Educação da Universidade de São Paulo, 1999.

FREIRE, P. Conscientização e alfabetização: uma nova visão do processo. Revista de Cultura da Universidade do Recife, n.4, p. 4-22, Abr./Jun., 1963. Disponível em: (http://forumeja.org.br/df/sites/forumeja.org.br.df/files/est.univ_.pdf). Acesso em: 20 mar. 2021.

FREIRE, P. Extensão ou comunicação? 4 ed. Rio de Janeiro: Paz e Terra, 1979.

FREIRE, P. Educação como prática da liberdade. 10 ed. Rio de Janeiro: Paz e Terra, 1980.

FREIRE, P. Pedagogia do oprimido. Rio de Janeiro: Paz e Terra, 2016.

GADOTTI, M. Alfabetizar e conscientizar: Paulo Freire, 50 anos de Angicos. São Paulo: Instituto Paulo Freire, 2014.

MACIEL, J. A fundamentação teórica do Sistema Paulo Freire. Revista de Cultura da Universidade do Recife, n. 4, p. 25-55, abr./ju. 1963. Disponível em: http://forumeja.org.br/df/sites/forumeja.org.br.df/files/est.univ_.pdf. Acesso: 30 mar. 2021.

PELANDRÉ, N. L. Ensinar e aprender com Paulo Freire: 40 horas 40 anos depois. 3 16 ed. Florianópolis: Editora da UFSC, 2009.

SIMÕES, J. Educação crítica e seu método. São Paulo: Edições Loyola, 1981.

STRECK, D.; REDIN, E.; ZITKOSKI, J. J. (Orgs.) Dicionário Paulo Freire. 2. ed., rev. Belo Horizonte: Autêntica, 2010. 